\title{
Aerosol Reduction In Dentistry: Minimizing Risk Of Covid 19
}

\author{
B. Lakhani, A. Sharma, V. Sanwalka, and P. Lakhani
}

\begin{abstract}
Introduction: The challenging times of COVID 19 pandemic pose a greater risk to dental professionals and patients. Since the worldwide outbreak, dental offices have been advised to disrupt regular functioning.

Aim and Objective: This article aims to discuss measures of infection prevention and control, special procedural recommendations to minimize disease transmission while reducing aerosol generation, surface disinfection and careful waste management to assist dental offices to limit the risk of COVID 19.

Conclusion: Adhering to the principles of infection control and non-aerosol generating practices in dental office could help control disease transmission, keeping the dental professionals and the patients safe.
\end{abstract}

Index Terms - AGPs; coronavirus; dentistry; PPE.

\section{INTRODUCTION}

Dental team is constantly exposed to aerosols and splatter which is a source of nosocomial infections for the operator, assistants and patients. An aerosol cloud of particulate matter and fluid often is evident during tooth preparation with a rotary instrument or air abrasion, air polishing, use of an air-water syringe and ultrasonic scaler [1]. Air contamination is expressed as microbial colony forming units per cubic meter $\left(\mathrm{CFU} / \mathrm{m}^{3}\right)$ of air measured with an air sampler and higher levels were observed for cavity preparation $\left(24-105 \mathrm{CFU} / \mathrm{m}^{3}\right)$ and for ultrasonic scaling (42-71 CFU/m3), while lower levels were reported for extraction (9-66 $\left.\mathrm{CFU} / \mathrm{m}^{3}\right)$ and for oral examination (24$\left.62 \mathrm{CFU} / \mathrm{m}^{3}\right)$. Aerosols, which are responsible for the transmission of micro-organisms by air, consist of small particles named droplet nuclei $(1 \pm 5 \mu \mathrm{m})$ or droplets $(>5 \mu \mathrm{m})$. Droplet nuclei can stay airborne for hours, transport over long distances and contaminate surfaces by falling down in a range of 1 meter (3ft) [2].

The novel coronavirus disease 2019 (covid-19) presents an important and urgent threat to global health. Since the outbreak in early December 2019 in the Hubei province of the People's Republic of China, the number of patients confirmed to have the disease has exceeded 4563458 in more than 160 countries, and the number of people infected

Published on June 24, 2020.

B. Lakhani, Dantika Dental Clinic, India.

(corresponding e-mail: bhanu.lakhani ${ }^{\circledR}$ gmail.com).

A. Sharma, Rajathan Dental College, India.

(e-mail: drapoorva25@gmail.com).

V. Sanwalka, Smile Dental Clinic, UK.

(e-mail: drsanwalka@ ${ }^{@ m a i l . c o m) . ~}$

P. Lakhani, Surendera Dental College, India.

(e-mail: drpulkitlakhani@gmail.com). is probably much higher. The pathogen was identified as 2019 novel coronavirus (2019-nCoV), and the disease was named coronavirus disease 2019 (COVID-19) [3].

Dental care settings invariably carry the risk of 2019$\mathrm{nCoV}$ infection due to the specificity of its procedures and microorganisms can be transmitted in dental settings through inhalation of airborne microorganisms that can remain suspended in the air for long periods, direct contact with blood, oral fluids, or other patient materials, contact of conjunctival, nasal, or oral mucosa with droplets and aerosols containing microorganisms generated from an infected individual and propelled a short distance by coughing and talking without a mask and indirect contact with contaminated instruments and/or environmental surfaces [4].

As recommended by Harrel and Molinari, the three levels of defense in the reduction of aerosols are the use of a personal protective barrier such as masks, gloves, and safety glasses, routine use of a pre-procedural rinse, and use of high evacuation device [1]. The article aims to elaborate the recommendations for infection prevention and control, reducing airborne generation and contamination, procedural modifications and disinfection of dental office to minimize the risk of COVID-19 transmission in dental operatory (Table 1).

\section{INFECTION PREVENTION AND CONTROL}

\section{A. Hand hygiene}

It is advisable to wash hands with plain or antimicrobial soap, tested according to EN1500 (Europe) or ASTEM E_1838/2011 (USA) and water when visibly dirty or contaminated with proteinaceous material. Following this, use an alcohol-based rub (isopropyl alcohol or isopropanol $60 \%$ volume), in accordance with EN1500 (Europe) or ASTM E-1838/2011 (USA) for routine hand antisepsis.

Hand hygiene should be performed each time before and after having direct contact with patients; after removing gloves; before handling any device for patient care, regardless of whether or not gloves are used; after contact with body fluids or excretions or mucous membranes.

Technique:

a) Handrub: Apply a palmful of the product and cover all surfaces of the hands. Rub hands until hands are dry (Fig. 1).

b) Handwash: Wet hands with water and apply the amount of product necessary to cover all surfaces. Vigorously perform rotational handrubbing on both hand palms and backs, interlace and interlock fingers to cover all surfaces. Rinse hands with water and dry thoroughly with a single-use towel. Use running and clean water whenever 
possible. Use towel to turn off tap/faucet (Fig. 2). Avoid using hot water, as repeated exposure to hot water may increase the risk of dermatitis.
Liquid, bar, leaf or powdered forms of plain soap are acceptable when washing hands with a non-antimicrobial soap and water [5].

TABLE I: MINIMIZING AEROSOLS IN DENTISTRY

\begin{tabular}{|c|c|c|c|c|}
\hline \multirow{11}{*}{ I } & \multirow{11}{*}{$\begin{array}{l}\text { Infection Prevention } \\
\text { and Control }\end{array}$} & \multirow[t]{2}{*}{ Hand Hygiene } & Handrub & Alcohol-based rub (60\% by volume) \\
\hline & & & Handwash & antimicrobial \\
\hline & & \multirow[t]{7}{*}{ Personal Protective Equipment } & \multirow[t]{4}{*}{ Mucous Membrane Protection } & Goggles \\
\hline & & & & Face Shield \\
\hline & & & & Surgical Mask \\
\hline & & & & N95 Respirator \\
\hline & & & Gloves & Double, Disposable, Latex/Powder Free \\
\hline & & & Clothing & Coverall non-woven and laminated Fabric \\
\hline & & & Head Cover & Single Use, Fluid Resistant \\
\hline & & \multicolumn{3}{|l|}{ Minimize Contact } \\
\hline & & \multirow{10}{*}{$\begin{array}{l}\text { Pre-Procedural Mouth Rinse } \\
\text { Restorative Dentistry and } \\
\text { endodontic }\end{array}$} & \multicolumn{2}{|c|}{$1 \%$ hydrogen peroxide or $0.2 \%$ povidone-iodine } \\
\hline \multirow{26}{*}{ II } & \multirow{26}{*}{$\begin{array}{l}\text { Procedural } \\
\text { Modifications }\end{array}$} & & \multicolumn{2}{|c|}{ Rubber Dam } \\
\hline & & & \multicolumn{2}{|c|}{ Chemo-mechanical Caries Removal } \\
\hline & & & \multicolumn{2}{|c|}{ ART (Atraumatic Restorative Technique) } \\
\hline & & & \multicolumn{2}{|c|}{ Silver Diamine Fluoride } \\
\hline & & & \multicolumn{2}{|c|}{ SMART (Silver Modified Atraumatic Restorative Technique) } \\
\hline & & & \multicolumn{2}{|l|}{ Low Speed Micromotors } \\
\hline & & & \multicolumn{2}{|l|}{ Monoblocking with Composites } \\
\hline & & & \multicolumn{2}{|l|}{ Hall Technique } \\
\hline & & & \multicolumn{2}{|l|}{ Pre-formed Crowns } \\
\hline & & Oral Radiology & Extra-Oral & Double Barrier \\
\hline & & & Intra-Oral & Triple Barrier \\
\hline & & Esthetic Dentistry & Prepless Veneers & \\
\hline & & & Direct Composites & \\
\hline & & Prosthodontics & Scaling and Polishing & \\
\hline & & & Gum Surgeries & \\
\hline & & & Osteotomies for Implants & \\
\hline & & & LASERS & \\
\hline & & & No Piezosurgery Units & \\
\hline & & & Grafting & \\
\hline & & Oral Surgery & Exodontia & \\
\hline & & & Tooth Sectioning & Intermittent drilling without Irrigation \\
\hline & & & Bonding & Slow Speed Polishing \\
\hline & & & & Chip Blower for Gentle Dry \\
\hline & & & Inter-proximal Reduction & Hivac Suctions \\
\hline & & & Debonding & $\begin{array}{l}\text { Debonding Bur at Slow Speed without Water } \\
\text { Spray }\end{array}$ \\
\hline & & & Micro-Implants & Moist Gauze; No Water Spray \\
\hline & & High Volume Evacuators & & \\
\hline & & Room Filtration & High Efficiency Particulate Air & IEPA) Filters \\
\hline III & Reducing Airbourne & Fumigation & Formaldehyde Vapours & \\
\hline & & & Vapour Phase Hydrogen Peroxi & \\
\hline & & & Chlorine Dioxide Gas & \\
\hline & & Surface Disinfectants & $2 \%$ Gluteraldehyde Solution & \\
\hline & & & $1 \%$ Sodium Hypochlorite Solut & \\
\hline & & & 3\% Hydrogen Peroxide Solutiol & \\
\hline IV & Disinfection & UV-C Light Chambers & & \\
\hline & & Wet Mopping - Three Bucket T & que & \\
\hline & & Waterlines & $5 \%$ Sodium Hyypochlorite Solu & \\
\hline $\mathrm{V}$ & & UN approved Yellow Container & erred over Bags & \\
\hline V & Waste Management & Segregated Space for Waste Co & & \\
\hline
\end{tabular}

\section{B. Personal protective equipment (PPE Kit)}

Consistent use of full-body personal protective equipment (PPE) (Fig. 3, a) can diminish the risk of infection for healthcare workers when standards for protective clothing and fabric permeability for viruses are adhered to. Covering more parts of the body leads to better protection but usually comes at the cost of more difficult donning (putting-on) or doffing (taking-off) and user comfort and may therefore sometimes even lead to more contamination [6].

\section{B. 1. Mucous membrane protection}

1. Goggles: Although an effective barrier method, these should be chosen after thorough inspection. Good seal with the skin of the face while covering the eyes and surrounding areas is necessary with a flexible frame that easily fits all face contours without too much pressure. They should be able accommodate prescription glasses wherever needed. Anti-fog and scratch-resistant ones have proven to enhance intra-operative field visibility [5]. 


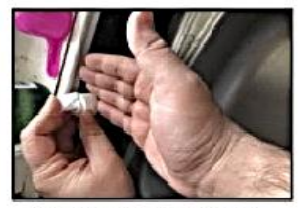

Apply a palmful of product

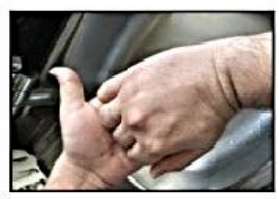

Back of fingers to opposing palms with fingers interlocked

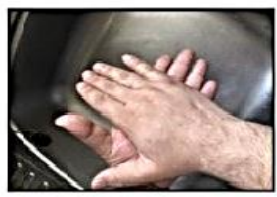

Rub hands palm to palm

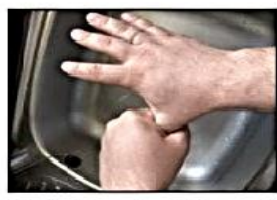

Rotational rubbing of right thumb clasped in left hand and vice versa

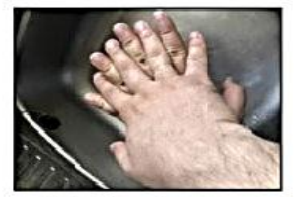

Right palm over left dorsum with

interlaced fingers and

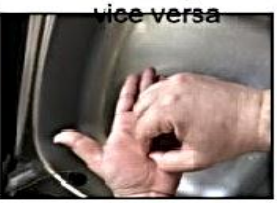

Rotational rubbing backwards and forwards of of right hand in left palm and vice versa

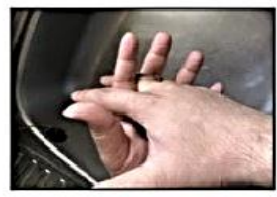

Palm to palm with fingers interlaced

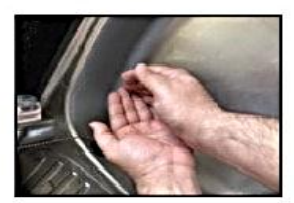

Once dry, your hands are safe

Fig. 1. Hand Rub Technique: 20-30 seconds.

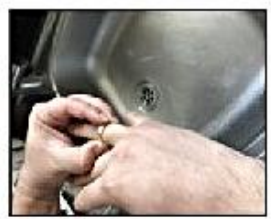

Remove all Jwellery

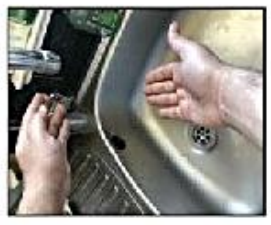

Wet hands with water

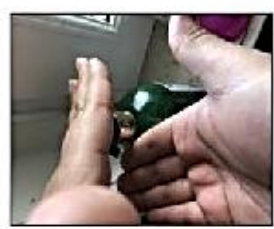

Apply enough soap to cover all hand

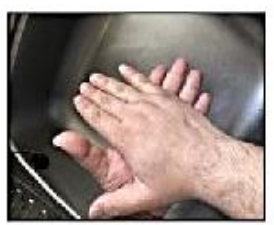

Rub hands palm to palm

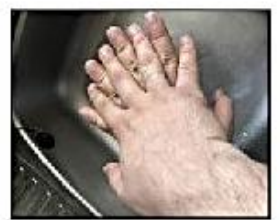

Right palm over left dorsum with interlaced fingers and vice versa

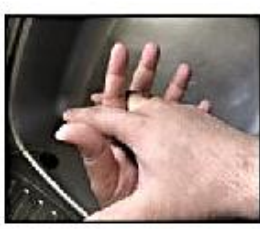

Palm to palm with fingers interlaced

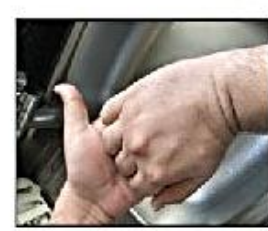

Back of fingers to opposing palms with fingers interlocked

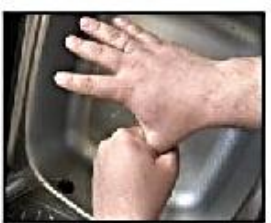

Rotational rubbing of right thumb clasped in left hand and vice versa

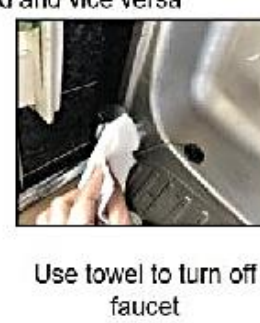
faucet

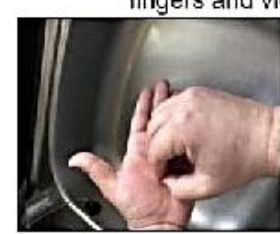

Rotational rubbing, backwards and forwards of of right hand in left palm and vice versa

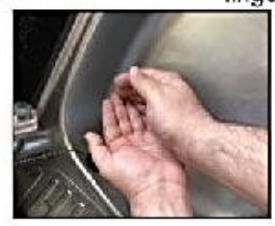

Rinse hands with water

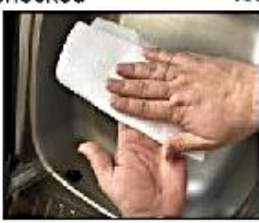

Dry thoroughly with single use towel

Fig. 2. Hand Wash Technique: 40-60 seconds.

2. Face shields: These are made of clear plastic and provide good visibility to both the wearer and the patient. Usually an adjustable band allows a good fit around the forehead. It should cover the sides and length of the face. Both autoclavable and disposable ones are available to suit the individual operatory requirements [5], [7].

3. Respiratory Protection:

a) Surgical Face Mask - These provide barrier protection against droplets that are considered to be the primary route of COVID transmission. However, they may not adequately protect against aerosol or airborne particles, since they do not effectively filter small particles from the air, allow leakage around the mask, and cannot be fit tested [8].

Since the spread of COVID through the air has not been ruled out, $\mathrm{CDC}$ recommends a NIOSH-approved respirator equivalent to or greater than the $\mathrm{N}-95$. b) Respirator - A personal protective device that is worn on the face, that covers at least the nose and mouth, and is used to reduce the wearer's risk of inhaling hazardous airborne particles, gases, or vapours. Before understanding the specific indications for selection of a particular type, it is important to be cognizant of various types of respirators available that include:

- Particulate Respirators, which filter out airborne particles;

- Gas Masks, which filter out chemicals and gases;

- Airline Respirators, which use compressed air from a remote source;

- Self-contained Breathing Apparatus, which include their own air supply [9].

Particulate respirator, also known as "air-purifying respirators", protect against particles by filtering them out of 
the air as it is breathe. These do not protect against gases or vapours. These include:

- Disposable or Filtering Facepiece Respirators (FFRs) (Fig. 3, b).

- Reusable Elastomeric Respirators: The facepiece is cleaned and reused but the filter cartridges are discarded and replaced when they become unsuitable for further use. Efficiency is comparable to disposable FFRs if used correctly.

- Powered Air Purifying Respirators (PAPRs): These use HEPA filters (high-efficiency particulate air filters) and provide a higher level of protection than disposable and reusable respirators.

Further, respirators that filter out at least $95 \%$ of airborne particles during "worse case" testing using a "mostpenetrating" sized particle are given a 95 rating, those that filter out at least $99 \%$ receive a "99" rating, and those that filter at least $99.97 \%$ (essentially $100 \%$ ) receive a " 100 " rating.

Respirators in this family are further rated for protection against oils as N: Not resistant to oil; R: somewhat Resistant to oil; or P: strongly resistant (oil Proof).

Thus, there are nine types of disposable particulate respirators:

- N-95, N-99, and N-100;

- R-95, R-99, and R-100;

- P-95, P-99, and P-100.
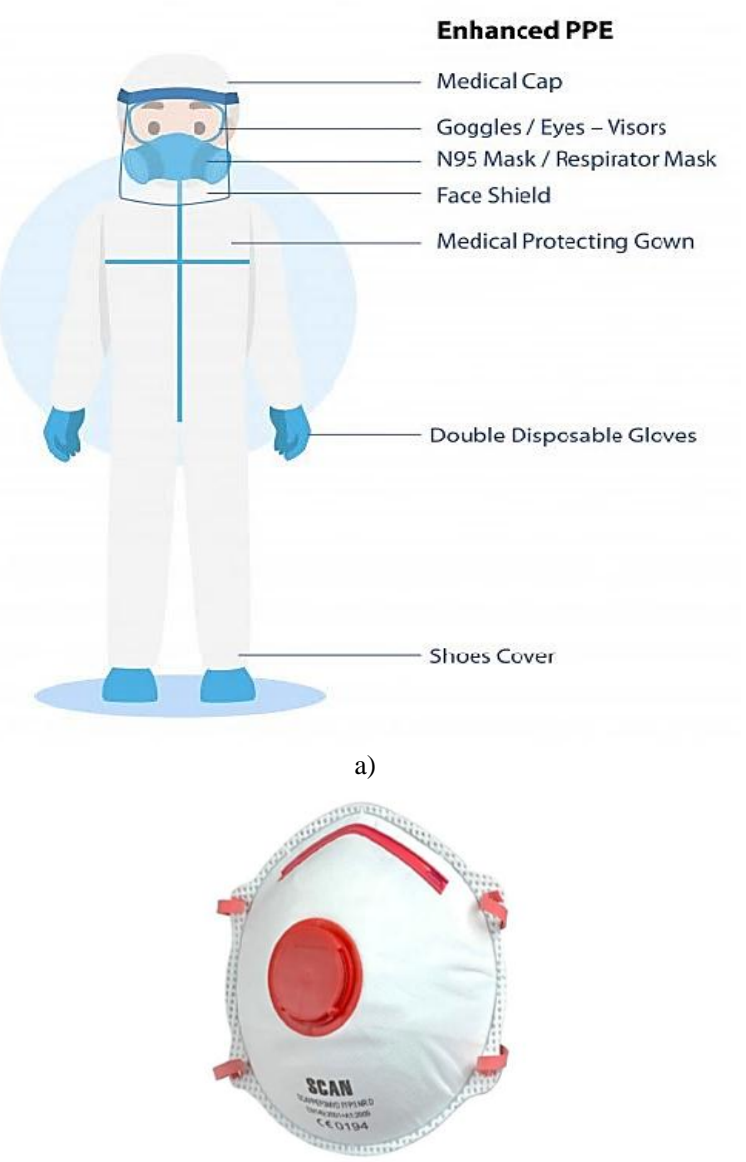

b)

Fig. 3. Personal protective equipment: a) PPE Kit; b) Filtering Facepiece Respirators.

\section{$B$ 2. Understanding and Selecting Respiratory Protection} Devices

The CDC recommends that dental health care workers protect themselves from any disease spread through the air (airborne transmission) by:

- Wearing a respirator at least as protective as a fit-tested $\mathrm{N}-95$ respirator.

- Put on correctly \& worn during the exposure.

- Fit snugly against the user' $\mathrm{s}$ face to ensure that there are no gaps between the user' s skin and respirator seal.

- Resting over the nose, not chin [8].

A powered, air-purifying respirator (PAPR) with a hood may protect better than an N95 mask with a gown but is more difficult to don [6].

National Institute for Occupational Safety and Health (NIOSH) approved disposable respirators are marked with the manufacturer's name, the part number $(\mathrm{P} / \mathrm{N})$, the protection provided by the filter (e.g., N-95), and "NIOSH." This information is printed on the facepiece, exhalation valve cover, or head straps [8].

The particulate respirators in different countries may have different names (e.g. FFP3 recommended by NHS in the UK) than those certified by NIOSH in the United States. If these respirators pass testing programs comparable to those used for N-95 respirators, they should protect against COVID 19.

\section{B 3. Facial Hairstyles and Filtering Facepiece Respirators} (Fig. 4)

The OSHA Respiratory Protection standard states that respirators shall not be worn when facial hair comes between the sealing surface of the facepiece and the face Short moustaches, sideburns, and small goatees that are neatly trimmed do not present a hazard.

However, some other types of respirators do not require a face seal, and thus, usually can be worn with facial hair, such as loose fitting powered air-purifying respirators and hooded powered air-purifying respirators and hooded powered air-purifying respirators [9].

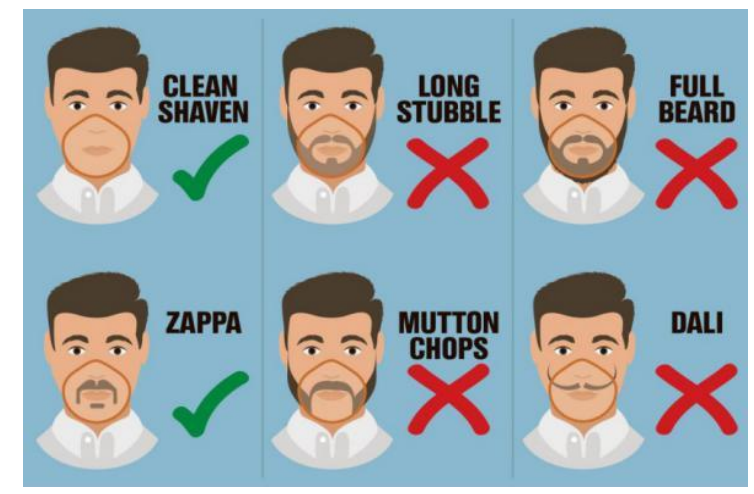

Fig. 4. Facial hairstyles and respirators.

\section{B 4. Gloves}

Double gloves are recommended over single gloves, to decrease the potential risk of virus transmission to the health worker as a result of glove perforations, needle-stick injuries and contamination of hands when removing PPE. The outer glove should have a long cuff, reaching well above the wrist, and ideally to the mid-forearm [10]. Nitrile gloves are 
recommended because they resist chemicals, certain disinfectants, such as chlorine, and because there is a high rate of allergies to latex and contact dermatitis. Nonpowdered gloves are preferred to powdered gloves as the latter may also cause sensitivity [5].

\section{$B$ 5. Clothing and covering for clothing}

The choice of PPE for covering clothing should be either a disposable gown and apron, or a disposable coverall and apron; the gown and the coverall should be made of a fabric, preferably non-woven and laminated that has been tested for resistance to penetration by blood and other body fluids or by bloodborne pathogens. The apron should preferably be made of polyester with PVC-coating or other waterproof material and covering approximately $70-90 \mathrm{~cm}$ width $\mathrm{x}$ 120-150 cm length. If disposable aprons are not available, a heavy-duty, reusable waterproof apron can be used, provided that it is appropriately cleaned and disinfected between patients [5]. A long gown may be the best compromise between protection and ease of doffing. Coveralls may be more difficult to doff [6]. Fig. 5 describes the Don Doff sequence for personal protective equipment.

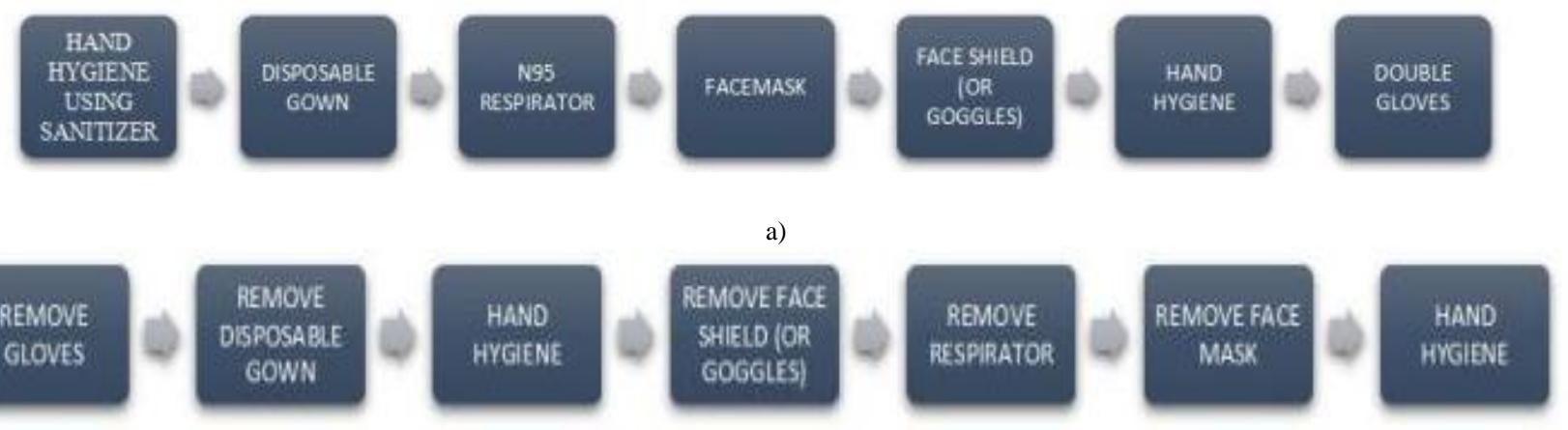

b)

Fig. 5. PPE sequence:

a) DON; b) DOFF

\section{B 6. Shoe Covers}

Single use, fluid-resistant shoe covers are recommended that are adjustable and stay securely in place once adjusted [11].

\section{B 7. Head cover}

Single-use head covers are preferred and should be fluidresistant, in order to prevent exposure to splashes of body fluids to the skin and hair of the head and neck [5].

\section{Minimize contact}

Sites within the operatory as well as other sections of dental office like reception, waiting areas, billing counters etc., should be demarcated clearly for the specific patient groups, waiting queue should be minimized to 1 patient per operator and communal areas should allow for 2 metre separation, ideally marked on chairs and flooring [12].

Furniture and equipment in the dental office set-up should be minimal. Only those essential for the operating procedure should be present. Patients should be discouraged for accompanying attendants unless undergoing critical care procedures. Rooms should always be closed with appropriate independent ventilation systems, and entry/exit should be minimized. All contact surfaces should be thoroughly covered with double layer of cellophane sheets [13].

\section{Pre-procedural mouth rinse}

Use of pre-operative antimicrobial mouth rinse reduce the microbial count in the oral cavity and aerosols generated during the procedure [14], [15]. Therefore, several associations have recommended the use of pre-procedural mouth rinse as measure to reduce the potential risk of infection transmission during dental treatment. Various authors recommend $1 \%$ hydrogen peroxide, $0.2 \%$ chlorhexidine (CHX), $2 \%$ povidine-iodine or $2 \%$ Listerine for 30 seconds prior to procedures. However, National Health Commission of the People's Republic of China have reported that $0.2 \% \mathrm{CHX}$ to not be effective against SARSCOV2 [16]. American Association of Endodontics, Indian Endodontic Society and National Health Commission of the People's Republic of China have therefore, recommended the use of $1 \%$ hydrogen peroxide or $0.2 \%$ povidone-iodine as pre-procedural mouth rinse [17], [18].

\section{PROCEDURAL MODIFICATIONS}

The aim of the treatment should be to:

1. Reduce the generation of aerosol by eliminating the usage of aerosol producing procedures (AGPs) and/or apparatuses like the air turbine drills and ultrasonic instruments in practice.

2. Have a critical approach towards protecting patients while addressing their dental needs.

3. Reduce 'doctor-to-patient' contact by minimizing chairside time.

4. Perform all safety measures for the operators as well as support staffs even when carrying-out basic procedures.

\section{A. Restorative dentistry and endodontics}

1. Rubber Dam: As is generally perceived, with rubber dam in place, $98.5 \%$ of the microbial content of such aerosols is shown to be eliminated, as is continued touch recontamination of the gloved hands of dentist and nurse with the patient's oral mucosa [19].

2. However, Al-Amad et al in 2017 quantitatively assessed the bacterial contamination of the dentist's head and to evaluate whether it is affected by using a rubber dam. 
They concluded that the rubber dam seems to result in significantly higher aerosol levels on various areas of the dentist's head, requiring that dentists cover their heads with suitable protective wear [20]. Due to the lack of further evidence and the established benefits of rubber dam, Indian Endodontic Society continues to highly recommend the use of rubber dam isolation with high volume saliva ejectors.

3. Carious Lesions Not Involving Pulp: Non-Aerosol Generating Procedures for Management of Carious Lesions should be preferred like:

3.1. Chemo Mechanical Caries Removal (CMCR) Agents: Papacarie is a CMCR product consisting basically of papain and chloramine, which together are responsible for the Papacarie's bactericide, bacteriostatic and antiinflammatory characteristics. Bussadori et al [21] and Hafez et al [22] concluded that Papacarie was effective in removing infected dentin, while preserving the deeper layer of affected dentin and does not adversely affect the microleakage of composite restorations and provides a suitable surface for bonding.

3.2. Atraumatic Restorative Technique: This involves the use of a sharp spoon excavator to remove only as much carious tissue from the floor as is required to allow adequate depth of the cavity so that a stable restoration of sufficient bulk can be placed.

3.3. In young children and in the geriatric population, the carious lesion can be arrested with the application of Silver Diamine Fluoride (SDF) without removing any carious tissue. No further restoration is required after SDF application. However, if food lodgment is a matter of concern, GI/RMGI restorative material can be placed over the SDF treated carious dentine. This is called Silver Modified Atraumatic Restorative Technique (SMART) [23].

3.4. Choice of Restoration: Glass Ionomer (GI) [24] or Resin Modified Glass Ionomer Restorative Cement-RMGIC is preferred wherever possible. If composite resin restorations are placed, use of self-etch bonds are preferred in order to minimize the use of a three way syringe to wash off excess etchant prior to bonding [25].

4. Carious Teeth with Symptomatic Irreversible Pulpitis: It is advisable to avoid pulpectomies in primary teeth. Extraction and placement of space maintainer where required are preferable. When performing pulpectomies, chemomechanical caries excavation can be adducted with spoon excavator or slow speed micromotor handpiece without water spray until pulp is exposed [26].

5. Carious Teeth with Necrotic Pulp: Initiating root canal treatment is inevitable. In order to minimise aerosols, use a micromotor for access openings and single sitting RCTs should be done to minimise the number of appointments.

6 Post Endodontic Restorations: Full crowns to be avoided since it will require the use of a high speed air turbine handpiece. The following options can be chosen to protect the endodontically treated tooth and make it functional.

6.1. Monoblocking with composite resin - Cuspal coverage of post endodontic teeth can be done using restorative composite resins in order to prevent fractures

6.2. Post and core restorations can be done following usual protocol.

6.3. Stainless steel crown/Hall technique.

\section{B. Oral radiology}

1. Extra Oral: Chin Rest and rotary arms to be covered with disposable polythene covers and changed for every patient. In order to make it more effective, 2 layer barriers can be placed so that 1 st layer in contact with patient can be removed by patient himself/herself and 2 nd layer by the operator.

2. Intra Oral: Intra-oral sensors are more prone to act as contaminant delivery surfaces and 3 layers of disposable polythene covers have to be used. Outermost cover is removed by patient himself/herself and disposed in designated waste receiver, 2nd layer is removed by assistant and the third layer removed by clinician and then the sensor is put in the machine [27].

\section{Esthetic dentistry}

1. Prep-less indirect veneers are quiet advantageous considering the current risks involved. Smile designing cases requiring mostly addition of restorative materials can be performed by doing minimal tooth preparation with a micromotor and diamond burs. Lab fabricated veneers with minimal thickness can be fabricated [28].

But cases requiring significant tooth reduction for improving alignment of teeth should be deferred or treated with precaution.

2. Direct composite restorations: Class 4 restorations for repair of a chipped tooth can be performed following usual bonding protocols.

3. Diastema Closure: Since the procedure entails only addition of restorative material can be performed without any tooth preparation.

\section{Prosthodontics}

Prosthodontic procedures can be carried out with certain precautions:

1. Impression Techniques: Digital impressions using intraoral scanners are preferred in order to prevent spread of infection through cross contamination by making impressions and pouring casts [29].

During conventional impression procedure, either disposable trays can be used or autoclavable trays used after following meticulous sterilization protocol. There is no preference to plastic or steel as the average survival time of coronavirus on both surfaces is approximately $72 \mathrm{hrs}$ [30].

2. Ultrasonic cleaners after washing instruments under running tap water is recommended as these do not produce any aerosols during their function.

3. Disinfection:

3.1. Impression disinfection: Immersion is better than spraying that increases risk for assistants. Impressions should be packed in two layers of airtight bags prior to dispatch. Both Alginate and Elastomeric impressions can be disinfected using $1 \%$ Sodium hypochlorite solution, Quaternary ammonium compounds or glutaraldehyde based. The same technique is preferred for wax rims and wax bites. These should be immediately enclosed in a sealed plastic bag for proper contact time.

3.2. Acrylic appliances: Povidone Iodine or $1 \%$ Sodium hypochlorite are preferred. Avoid storing prostheses in a disinfectant. Instead rinse thoroughly after disinfection and store acrylic items in diluted mouthwash until inserted [31]. 
3.3. Gypsum casts are difficult to disinfect. Microwave irradiation of the casts for 5 minutes at $900 \mathrm{~W}$ does give high level disinfection of the gypsum casts.

4. Recommendation for dislodged crowns/bridges: Dislodged prosthesis should be thoroughly cleaned in running water and ultrasonic cleaners followed by disinfection protocol before re-cementation. Faulty or fractured prosthesis can be fabricated after standard impression techniques.

\section{E. Periodontics}

1. Scaling: Ultrasonic scalers should be avoided. Only hand instruments to be used with intermittent rinsing with $\mathrm{H}_{2} \mathrm{O}_{2}$ or polyvinylpyrrolidone (PVP) iodine powder or Chlorhexidine (CHX) every 10 minutes.

2. Surgeries: All periodontal surgeries are fine as long as there is no usage of power driven/ultrasonic instruments.

3. Osteotomies for implant site preparation is possible in clinical situations at speeds as low as 50-100 rpm without the use of saline for irrigation. For bone expansion, expansion screws or convex osteotomes augmented by performing a GBR (Bone grafting) procedure can be performed with usual protocols. Immediate implant placements and flap-less preparations do not require too much osteotomy site preparation and are preferred. Few drops of irrigation with least water flow on your physiodispensor for the pilot drill with heavy motor suction can be used but with extreme care to prevent splatter.

4. LASERS can be used as they promise better hemostasis, reduced aerosols, good postoperative healing and improved intra-operative control.

5. Use of Piezosurgery units for any procedures indicated is best avoided due to obvious aerosol production.

6. No autogenous grafting using trephine or piezosurgery is indicated due to increased aerosols, higher morbidity and chances of contamination [17].

\section{F. Oral surgery}

1. Exodontia: As a standardized protocol, it should be performed as usual under strict sterilization protocols. Sectioning, if needed should prefer use of chisel and mallet. Using drills for bone reduction with irrigation could lead to splatter and should be avoided. Drilling if unavoidable, should be intermittent without irrigation to avoid external source of splatter with breaks to take a sip of cold water, which should be removed using a high vacuum suction. Patients should refrain from spitting or gargling during the procedure.

2. Raising flaps and suturing, if needed, can be carried out as always. Pressure pack with a gauze and routine post extraction post op instructions. Nonetheless, patient should be given instructions for a safe method of gauze disposal.

3. Abscess drainages, opurculectomies can be performed as always [32].

\section{G. Orthodontics}

Orthodontic procedures may be safely performed considering relatively lesser risk as it involves minimal AGPs.

1. Aligners: The use of aligners as a treatment modality can be encouraged in Orthodontic offices as modern aligner techniques can bring about efficient tooth movement with more spaced out appointments, reduced chair-side time and even minimum intra-oral treatments and almost negligible aerosol generation during the treatment.

2. Changing arch wires, ligatures or active components of the fixed appliance must be performed with utmost caution and gentleness to avoid any fly away or laceration to patient/doctor.

3. Bonding of orthodontic attachments should be modified such that polishing is performed using a rubber cup with low speed micromotor, followed by etching with usual procedure, wash off using a syringe and needle in slow manner to reduce splash of water, chip blower to gently air dry the surface and then follow usual bonding procedure. Extreme care to be taken to avoid splatter.

4. Interproximal enamel reduction (IPR) using IPR strips or oscillating saw should be done very gently using water in a syringe to wash accompanied with high vacuum suction.

5. Debonding of brackets can be performed as usual by appropriate instrumentation and using low speed micromotor without water spray and followed be minimal polishing.

6. Placement of micro-implants and bone screws can be done with strict sterilization but use of three way jet should be avoided. To maintain field of vision, use moist gauze on the surgical site is highly suggested [34].

\section{REDUCE AIRBOURNE CONTAMINANTS}

\section{A. High volume evacuators}

The use of a high-volume evacuator, or HVE, usually with a large opening (usually 8 millimeter or greater) and is attached to an evacuation system that will remove a large volume of air (up to 100 cubic feet of air per minute) has been shown to reduce the contamination arising from the operative site by more than $90 \%$ [2]. Furthermore, Heating, Ventilation \& Air Conditioning (HVAC) system should equipped with a twin coil unit or another heat recovery device that guarantees $100 \%$ air separation between return and supply side. It is even more important to highlight that the air vents should be planned outside the operatory with due permission from air quality control board and should be placed at safe distance from the dental chair and air conditioner compressors [34].

\section{B. Room filtration and treatment}

It is mainly used to remove all water mist and splashes outside the mouth, to filter and disinfect, and to protect the environment and medical staff. It basically uses built-in high power blower that pushes air through a series of filtration units viz., Primary filter, UV light, Plasma disinfection and High Efficiency Particulate Air (HEPA) filter and together trap viruses and germs $\geq 0.3 \mu \mathrm{m}$ with $99.97 \%$ efficiency. UV light inside the unit has an intensity of $1210 \mathrm{uw} / \mathrm{cm}^{2}$ and wavelength $280 \mathrm{~nm}$, killing viruses and bacteria [35]. Various prototypes are already available to deal with the growing demands like, ExtraOral Suction DS1000 (Fig. 6, a), VacStation (Fig. 6, b), Ajax Droplets and Aerosols Terminator DW2530 (Fig. 6, c). Furthermore, HEPA filter should be integrated into the air-conditioning system to filter air directly before recirculation. 


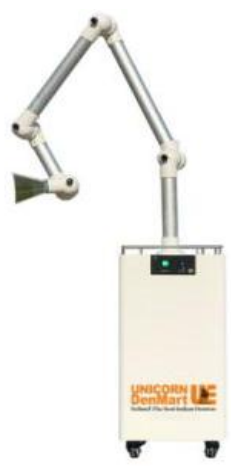

a)

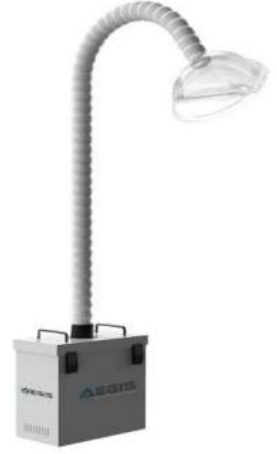

b)

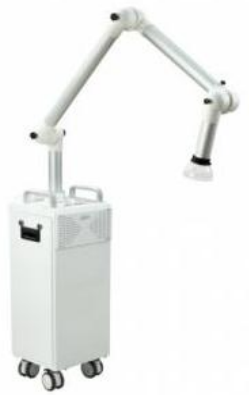

c)

Fig. 6. Oral suction system: a) ExtraOral Suction DS1000; b) VacStation;

c) Ajax Droplets and Aerosols Terminator DW2530.

\section{Fumigation}

Fumigants such as chlorine dioxide and hydrogen peroxide vapour (HPV) are two agents most frequently examined to decontaminate hospitals, animal research facilities, or similar environments [36]. Bali et al found formaldehyde based fumigators decreased the colony forming units $\left(\mathrm{cfu} / \mathrm{m}^{3}\right)$ in post-fumigation sampling a week later to below the acceptable limits $\left(35 \mathrm{cfu} / \mathrm{m}^{3}\right)$ of organisms in different samples and was found to be highly effective against Fungi and E. coli [37]. Chlorine Dioxide powder mixed with water releases chlorine dioxide gas and can effectively sterilize the room when left with windows closed for 1-1.5 hour followed by opening HVAC for 2-5 minutes [36]. Hydrogen peroxide was developed to be used as a vapor generated from a $30 \%$ to $35 \% \mathrm{H}_{2} \mathrm{O}_{2}$ solution or as an aerosol with concentration $5 \%$ to $12 \% \mathrm{H}_{2} \mathrm{O}_{2}$. Vapor-based process can be a dry system with vapor generated in a heated evaporator chamber with preheated supply lines or a wet system in which microcondensation of HPV forms a layer over all surfaces. For aerosol generation, nebulizer or fogging systems are used with one or more nozzles through which a fine mist of aerosol diameter of about $4 \mathrm{~mm}$ are generated. Aerosolized hydrogen peroxide can be supplied from outside the room and recirculated with the use of fans or additional ventilation [38].

\section{DISINFECTION}

1. Treatment area/patient care area: Highest zone of infection is within 3 meters (10 Feet) of dental chair [39].

1.1. All surfaces, such as the dental chair, dental light, drawer handles and countertops, should be cleaned and disinfected. Human coronaviruses can be efficiently inactivated by surface disinfection procedures with $62-71 \%$ ethanol, $0.5 \%$ hydrogen peroxide or $0.1 \%$ sodium hypochlorite within 1 minute [30].

1.2. Offices must cover high touch/clinical surfaces that are difficult to clean with protective covers, which are replaced after each patient.

1.3. If performing AGPs, do not begin disinfection after AGPs for the recommended 207 minutes i.e. before aerosol settles to the ground.

1.4. UltraViolet-C (UV-C) light chambers can be utilized for sterilization of all critical, heat resistant semicritical instruments and handpieces between patients since Coronaviruses are destroyed by ultraviolet $\mathrm{C}$ light (UV-C) exposure for $15 \mathrm{~min}$ [40].

1.5. Heat sensitive semi-critical items can be processed with high-level disinfection e.g. $2 \%$ Gluteraldehyde.

1.6. Use moistened wipe / cloth to clean all surfaces with freshly prepared disinfectant solution. (Eg: $1 \%$ Sodium hypochlorite or $3 \%$ hydrogen peroxide). Always discard remnant diluted solution [30].

1.7. Floor-Use Wet Moping 3-Bucket Technique:

1.7.1. Water followed by (ii) Detergent followed by (iii) Low Level Disinfectant like 3\% hydrogen peroxide, $1 \%$ Sodium hypochlorite or EPA approved agents.

1.7.2. Mop heads and cleaning cloths must be decontaminated regularly by Laundering (heat disinfection) with detergent and drying at $80{ }^{\circ} \mathrm{c}$ and changed frequently [5].

2. Reception and patient waiting area: High touch surfaces must be cleaned more frequently with detergent/disinfectant and preferable covered with double disposable barriers.

3. Disinfect water lines with $1 \mathrm{ml}$ of $5 \%$ sodium hypochlorite in $5 \mathrm{~L}$ of dental waterline.

\section{WASTE MANAGEMENT}

Large volumes of waste may be generated by frequent use of PPE and other disposable barriers and should be considered as infectious clinical waste. Potentially infectious and known infectious waste like dressings, soiled bandages, swabs should be discarded into UN approved orange bags followed by UN approved rigid containers for the duration of the COVID-19 response, suitable for alternative treatment, unless the waste has other properties that would require it to be incinerated. Also, a waste storage location should be designated inside the establishment to minimize exposure to personnel [5].

All practices should ensure that:

1. All outer packaging must be removed and recycled before an item is taken onto any ward or clinical area to avoid contamination or must be disposed as infectious clinical waste, if taken in clinical area [12].

2. All food waste must be disposed of in black bags/compostable bags.

3. Sharps which have been used to administer medicinal products like needles, ampoules, vials should be disposed of into UN approved rigid sharps boxes with yellow lids.

4. Sharps which have not been contaminated with medicinal products like blades, scissors or cannula should be 
disposed into UN approved yellow rigid sharps boxes with orange lids [5].

5. In summary, infectious clinical waste should be treated like any other infectious clinical waste, that is, as it would be for TB, hepatitis, etc., following national regulations.

\section{CONCLUSION}

Dentist are at a higher risk of contracting infectious airborne diseases because of the nature of their work involving various aerosol generating procedures. The current COVID 19 pandemic has brought along more challenges for the dentists and the auxiliary staff. Basic principles of infection control along with special procedural precautions at minimizing aerosol reduction could help limit the disease transmission from asymptomatic carriers. These guidelines may serve as a reference for dental offices to resume routine practice while safeguarding the health and well-being of their staff and patients.

\section{REFERENCES}

[1] Harrel SK, Molinari J. Aerosols and splatter in dentistry: a brief review of the literature and infection control implications. The Journal of the American Dental Association. 2004 Apr 1;135(4):429-37.

[2] Kobza J, Pastuszka JS, Brągoszewska E. Do exposures to aerosols pose a risk to dental professionals?. Occupational Medicine. 2018 Sep $13 ; 68(7): 454-8$.

[3] Wynants L, Van Calster B, Bonten MM, Collins GS, Debray TP, De Vos M, Haller MC, Heinze G, Moons KG, Riley RD, Schuit E. Prediction models for diagnosis and prognosis of covid-19 infection: systematic review and critical appraisal. BMJ. 2020 Apr 7;369.

[4] Liu L, Wei Q, Alvarez X, Wang H, Du Y, Zhu H, Jiang H, Zhou J, Lam P, Zhang L, Lackner A. Epithelial cells lining salivary gland ducts are early target cells of severe acute respiratory syndrome coronavirus infection in the upper respiratory tracts of rhesus macaques. Journal of virology. 2011 Apr 15;85(8):4025-30.

[5] World Health Organization Coronavirus disease (COVID-19) technical guidance: Infection prevention and control / WASH. Avaialable at https://www.who.int/emergencies/diseases/novelcoronavirus-2019/technical-guidance/infection-prevention-andcontrol Last accessed on 16 May 2020

[6] Verbeek JH, Rajamaki B, Ijaz S, Sauni R, Toomey E, Blackwood B, Tikka C, Ruotsalainen JH, Kilinc Balci FS. Personal protective equipment for preventing highly infectious diseases due to exposure to contaminated body fluids in healthcare staff. Cochrane Database of Systematic Reviews 2020, Issue 4.

[7] Roberge R. J. (2016). Face shields for infection control: A review. Journal of occupational and environmental hygiene, 13(4), 235-242.

[8] NIOSH[2020] Christopher Coffey, Maryann M. D’Alessandro, Jaclyn Krah Cichowicz. Respiratory Protection During Outbreaks: Respirators versus Surgical Masks. NIOSH Science Blog. April 9, 2020

[9] CDC. NIOSH-Approved Particulate Filtering Facepiece Respirators. Available

https://www.cdc.gov/niosh/npptl/topics/respirators/disp_part/default.h tml. Last accessed on 16 May 2020

[10] Phin NF. Requirements and technical specifications of personal protective equipment (PPE) for the novel coronavirus (2019-ncov) in healthcare settings.

[11] Sureshram T, Rajasekar S, Vadodaria K. Guidelines on Personal Protective Wearables Used For Protection Against Highly Infectious Diseases Such as Ebola, Sars and Avian Flu. International journal on textile engineering and processes. 2016 Apr:38.

[12] COVID-19 guidance and standard operating procedure. NHS England. VERSION 1, 15 APRIL 2020

[13] Souza RC, Costa PS, Costa LR. Dental Sedation Precautions and Recommendations during the COVID-19 Pandemic. Rev. Bras. Odontol. 2020;77:e1788.

[14] Waghmare SV. Comparative Evaluation of Colony Forming Unit Count on Aerobic Culture of Aerosol Collected Following PreProcedural Rinses of Either $0.2 \%$ Chlorhexidine Gluconate or $1 \%$ Stabilized Chlorine Dioxide During Ultrasonic Scaling: A Clinical and Microbiological Study. Journal of Contemporary Dentistry. 2018 May;8(2):70-6.

[15] Mani SS, Srikanthan S, Selvaraj B, Menaka V, Diwakar MK. Effectiveness of $0.2 \%$ chlorhex plus and $0.1 \%$ turmix as preprocedural mouthrinses on aerosol contamination produced by ultrasonic scalers: An interventional study. Journal of Dental Research and Review. 2020 Jan 1;7(1):5.

[16] Joshi AA, Padhye AM, Gupta HS. Efficacy of Two Pre-Procedural Rinses at Two Different Temperatures in Reducing Aerosol Contamination Produced During Ultrasonic Scaling in a Dental Setup-A Microbiological Study. Journal of the International Academy of Periodontology. 2017 Oct;19(4):138-44.

[17] Mathur N, Tyagi S, Dwivedi V, Narang A, Tyagi P, Nath KS DENTAL CONSIDERATIONS AMIDST COVID-19 SCARE. International Journal of Medical and Biomedical Studies. 2020 Mar $25 ; 4(3)$.

[18] Ather A, Patel B, Ruparel NB, Diogenes A, Hargreaves KM. Coronavirus Disease 19 (COVID-19): Implications for clinical denta care. Journal of endodontics. 2020 Apr 6.

[19] Marshall K. 'Dam it-it's easy!'-or is it?. British dental journal. 2017 Jun 9;222(11):839

[20] Al-Amad SH, Awad MA, Edher FM, Shahramian K, Omran TA. The effect of rubber dam on atmospheric bacterial aerosols during restorative dentistry. Journal of infection and public health. 2017 Mar 1;10(2):195-200.

[21] Bussadori SK, Godoy CH, Alfaya TA, Fernandes KP, MesquitaFerrari RA and Motta LJ. Chemo-mechanical caries removal with Papacarie: case series with 84 reports and 12 months of follow-up. J Contemp Dent Pract, 15: 250-3, 2014.

[22] Hafez MA, Elkateb M, El Shabrawy S, Mahmoud A, El Meligy O. Microleakage Evaluation of Composite Restorations Following Papain-Based Chemo-Mechanical Caries Removal in Primary Teeth. J Clin Pediatr Dent 2017;41(1):53-61.

[23] Nuvvula S, Mallineni SK. Silver Diamine Fluoride in Pediatric Dentistry. Journal of South Asian Association of Pediatric Dentistry. $2019 \mathrm{Jul} ; 2(2): 74$

[24] Heck K, Frasheri I, Diegritz C, Manhart J, Hickel R, Fotiadou C. Sixyear results of a randomized controlled clinical trial of two glass ionomer cements in class II cavities. Journal of Dentistry. 2020 Ap 17:103333.

[25] Patil AM, Deshpande S, Ratnakar P, Patil V, Surabhi R, Reza KM. To evaluate the fracture resistance of four core buildup materials: Amalgam, resin composite/dual cure, resin-modified glass ionomer, and SureFil packable composite restorative material under universal testing machine. International Journal of Oral Care and Research. 2020 Jan 1;8(1):5

[26] Casamassimo PS, Townsend JA, Litch CS. Pediatric Dentistry During and After COVID-19. Pediatric Dentistry. 2020 Mar 15;42(2):87-90.

[27] Chandy PE, Nasir MU, Srinivasan S, Klass D, Nicolaou S, Babu SB Interventional radiology and COVID-19: evidence-based measures to limit transmission. Diagn Interv Radiol. 2020 Mar 31.

[28] Sisler ZS. PREPARATION GUIDES: 10 STEPS TO MAXIMIZE SUCCESS FOR VENEER PREPARATION. Journal of Cosmetic Dentistry. 2020 Jan 1;35(4)

[29] Winkler J, Gkantidis N. Trueness and precision of intraoral scanners in the maxillary dental arch: An in vivo analysis. Scientific reports. 2020 Jan 24;10(1):1-1.

[30] Kampf G, Todt D, Pfaender S, Steinmann E. Persistence of coronaviruses on inanimate surfaces and its inactivation with biocidal agents. Journal of Hospital Infection. 2020 Feb 6.

[31] Chidambaranathan AS, Balasubramanium M. Comprehensive review and comparison of the disinfection techniques currently available in the literature. Journal of Prosthodontics. 2019 Feb;28(2):e849-56.

[32] Zimmermann M, Nkenke E. Approaches to the management of patients in oral and maxillofacial surgery during COVID-19 pandemic. Journal of Cranio-Maxillofacial Surgery. 2020 Apr 4.

[33] Sinha A. Sterilization and Disinfection in Orthodontics: A Literature Review. Indian Journal of Public Health Research \& Development. 2019 Nov 1;10(11).

[34] Avasth A. High Volume Evacuator (HVE) in reducing aerosol-an exploration worth by clinicians. J Dent Health Oral Disord The. 2018;9(3):165-6.

[35] Khanna R. Providing dental care in the current COVID-19 crisis Marshall Journal of Medicine. 2020;6(2):3.

[36] Beswick AJ, Farrant J, Makison C, Gawn J, Frost G, Crook B, Pride J. Comparison of multiple systems for laboratory whole room fumigation. Applied Biosafety. 2011 Sep;16(3):139-57.

[37] Bali R, Sharma P, Nagrath S, Gupta P. Microbial isolations from maxillofacial operation theatre and its correlation to fumigation in a 
teaching hospital in India. J Maxillofac Oral Surg. 2014;13(2):128132. doi:10.1007/s12663-012-0458-3.

[38] Kümin D, Albert MG, Weber B, Summermatter K. The hitchhiker's guide to hydrogen peroxide fumigation, part 1: introduction to hydrogen peroxide fumigation. Applied Biosafety. 2020:1535676020921007.

[39] Misra V, Bhardwaj A, Bhardwaj S, Misra S. Novel COVID-19Origin, Emerging Challenges, Recent Trends, Transmission Routes and Control-A Review. Journal of Contemporary Orthodontics. 2020 Jan;4(1):55-6.

[40] Castellano Realpe OJ, Gutiérrez JC, Sierra DA, Pazmiño Martínez LA, Prado Palacios YY, Echeverría G, de Waard JH. Dental Unit Waterlines in Quito and Caracas contaminated with Nontuberculous Mycobacteria: A potential health risk in dental practice. International Journal of Environmental Research and Public Health. 2020 Jan;17(7):2348. 